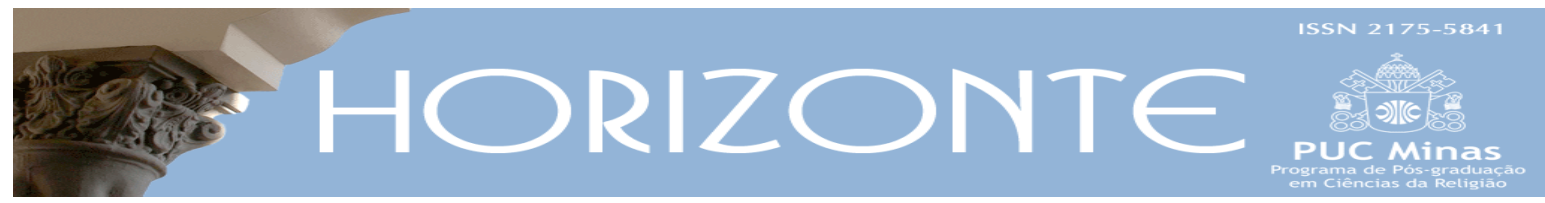

Temática Livre - Artigo original

DOI - 10.5752/P.2175-5841.2015v13n38p1051

\title{
O Coetus Internationalis Patrum no Concilio Vaticano II: apresentação e resultados de uma pesquisa ${ }^{1}$
}

\author{
The Coetus Internationalis Patrum in the Second Vatican Council: \\ presentation and results of a survey
}

Philippe Roy-Lysencourt*

\begin{abstract}
Resumo
O Coetus Internationalis Patrum (CIP), presidido por Mons. Lefebvre, foi o principal grupo de opositores ao espírito geral do Concílio Vaticano II. No presente artigo, o autor expõe brevemente suas pesquisas sobre o assunto em questão; pesquisas essas que culminaram na redação de uma tese de doutorado defendida no dia 3 de novembro de 2011. Depois de ter realizado uma história da pesquisa sobre o tema em questão e de ter apresentado as fontes utilizadas, o autor descreve a organização, a atividade e a estratégia do CIP, para então avaliar seu impacto sobre os esquemas do Concílio.
\end{abstract}

Palavras-chave: Coetus Internationalis Patrum; Concílio Vaticano II; Igreja Católica; Historiografia

\begin{abstract}
The Coetus Internationalis Patrum (CIP), chaired by Mgr. Lefebvre, was the main group of opponents to the general spirit of Vatican II. In this article, the author briefly exposes his research on the subject at hand; this research culminated in the writing of a doctoral thesis defended on November 3, 2011. After making a history of research on the topic at hand and having presented the sources used, the author describes the organization, activity and CIP strategy, to then evaluate its impact on the Council schemes.
\end{abstract}

Keywords: Coetus Internationalis Patrum; Vatican II; Catholic Church; History

\footnotetext{
${ }^{1}$ Este artigo foi construído com informações advindas dos seguintes arquivos: Acta et Documenta Concilio Oecumenico Vaticano II Apparando (Série I: Antepraeparatoria ; Serie II : Praeparatoria); Acta Synodalia Sacrosancti Concilii Oecumenici Vaticani II; Annuario pontifício; Archives de I'abbaye bénédictine de Solesmes; Archives de l'Archidiocèse de Diamantina; Archives de I'Université Catholique de l'Ouest; Archives de I'Université pontificale du Latran; Archives de la Fondazione per le scienze religiose Giovanni XXIII; Archives des Dominicaines du Saint-Esprit; Archives Diocésaines de Clermont-Ferrand; Archives du Séminaire d'Écône; Archivio Segreto Vaticano; Service des Archives de l'Archidiocèse de Sherbrooke.
}

Artigo recebido em 08 de maio de 2015 e aprovado em 25 de junho de 2015.

${ }^{*}$ Docteur en Histoire (Université de Lyon 3) et docteur en Sciences des religions (Université Laval). Chargé de cours en histoire du christianisme à l'Université Laval (Québec-Canada). Chargé de recherches au Fonds National de la Recherche Scientifique (FNRS Belgique). Fondateur de l'Institut d'Étude du Christianisme. Pays d'origine: France; Canadá. E-mail: philippe.roy.lysencourt@gmail.com 


\section{Introdução}

O desenrolar do Vaticano II - como o de vários outros concílios - poderia, de certa maneira, ser comparado às manobras de uma verdadeira guerra, com seus exércitos, oficiais e soldados, franco-atiradores e resistência. Cada esquema debatido no Concílio era como um campo de batalha do qual saíam um vencedor e um perdedor, mesmo o vencedor nunca tendo chegado a ser totalmente vitorioso, nem o perdedor chegado a ser totalmente derrotado. Em meio aos conflitos, homens se reagrupavam de acordo com afinidades de pensamento. O Coetus Internationalis Patrum (CIP) foi o grupo mais importante dentre aqueles que os historiadores do Concílio definiram como "minoria”. Por "minoria”, entende-se simplesmente os Padres conciliares que se opuseram à orientação tomada pelo Vaticano II e que juntos eram numericamente inferiores.

Devido a razões evidentes, a história dos perdedores só é escrita vários anos após os fatos. Às vésperas dos cinquenta anos do Vaticano II, apesar dos vários trabalhos realizados sobre o Concílio e sua importância, a história do CIP ainda não foi escrita. O presente autor começou a se dedicar a tal tarefa em 2007. Após 4 anos de estudo e pesquisa, o presente autor defendeu uma tese de doutorado sobre a história desse grupo em novembro de 2011. No presente artigo, escrito especialmente para revista Horizonte a pedido do professor Coppe Caldeira, busca-se delinear os principais resultados da pesquisa em questão. Depois de ter realizado uma história da pesquisa sobre o tema e de ter apresentado as fontes utilizadas, o autor descreve a organização, a atividade e a estratégia do CIP, para então avaliar seu impacto sobre os esquemas do Concílio.

\section{Historiografia e fontes}

O Coetus Internationalis Patrum, provavelmente em razão das dificuldades inerentes ao tratamento do tema, foi muito pouco estudado até o momento, apesar 
da importância que o grupo teve no Concílio. O autor do presente artigo não foi, porém, o primeiro a começar a pesquisar sobre tema tão pouco explorado. $\mathrm{O}$ primeiro entre os pioneiros neste campo de pesquisa foi o espanhol Salvador Gómez de Arteche y Catalina (1980), que defendeu uma tese de doutorado na faculdade de Direito da Universidade de Valladolid, intitulada Grupos "extra aulam" en el II Concilio Vaticano y su influencia. Nesta tese, o CIP não era mais do que um dos numerosos grupos que ele estudou, ocupando apenas algumas páginas. A pesquisa foi aprofundada pelo historiador Luc Perrin, que escreveu dois textos (cf. referências) sobre o tema: o primeiro é um capitulo de uma obra coletiva, publicada em Bologna em 1997 e o segundo - que é, na verdade, a tradução francesa aumentada do primeiro - é um artigo publicado na revista Catholica em 1999. Porém, o estudo do tema em questão foi logo abandonado. O grupo foi certamente mencionado em obras cientificas sobre o Vaticano II, notadamente na História do Concilio Vaticano II publicada sobre a direção de Giuseppe Alberigo (1997; 1998; 2000; 2003; 2005), mas, de uma maneira geral, os autores não fizeram mais do que repetir aquilo que os dois precursores tinham dito. Concentraram-se às vezes em um ou outro documento que não havia sido utilizado por eles, ou no tratamento de um esquema particular; ainda de maneira geral, não se chegou a usar documentos inéditos ou totalmente originais, já que estes podiam ser encontrados nas Acta et Documenta Concilio Oecumenico Vaticano II apparando (1960-1994) ou nas Acta Synodalia Sacrosancti Concilii Oecumenici Vatican II (1970-2000). Ou seja, no momento em que se decidiu iniciar a presente pesquisa, a temática ainda não tinha sido efetivamente explorada.

Ao lado destes trabalhos, é necessário ainda citar as pesquisas sobre os temas paralelos que, de maneira direta ou indireta, contribuíram para o avanço no conhecimento do CIP, fornecendo elementos sobre um ou outro personagem próximo ao grupo, esclarecendo eventos particulares ou tornando possível o conhecimento de correspondências. Sem pretender ser exaustivo, é necessário 
citar aqui os trabalhos de Nicla Buonasorte (2001; 2003; 2006) sobre o tradicionalismo italiano no Concílio, sobre o cardeal Siri², sem esquecer uma parte da correspondência entre Victor-Alain Berto e Mon. Luigi Carli, que ela publicou na revista Cristianesimo nella storia (BUONASORTE, 2001). Sobre Mons. Carli, é preciso enfatizar também a existência dos trabalhos de Emanuele Avallone (2009). Deve-se ainda mencionar as obras de Emanuele Gambino (1967), de Giuseppe Petralia (1989) e de Angelo Romano (2002) sobre o cardeal Ruffini, assim como sua correspondência conciliar, publicada por Francesco Michele Stabile (1990). E por fim, é necessário mencionar o trabalho de José Oscar Beozzo (2005) sobre a Igreja do Brasil no Vaticano II, no qual o autor evoca muito rapidamente a implicação de certos brasileiros no CIP, assim como as pesquisas recentes de Rodrigo Coppe Caldeira (2011) sobre os conservadores brasileiros no Concilio. Deve-se ainda mencionar a biografia de Bernard Tissier de Mallerais (2002) sobre Mons. Lefebvre, e as pesquisas de David Allen White (1993) sobre o Mons. de Castro Mayer.

Existia, então, uma pequena bibliografia que serviria de apoio. A partir dela, foi possível listar certos membros do grupo, fazer uma primeira lista e conhecer os personagens mais importantes, entre eles NN.SS. Lefebvre, de Proença Sigaud, de Castro Mayer e Carli, os cardeais Ruffini e Larraona, assim como D. Prou. Havia, portanto, uma boa base que permitiria a busca dos arquivos mais interessantes e a constituição de uma lista dos membros e simpatizantes do grupo em questão.

A busca dos arquivos foi uma operação que se revelou bastante delicada em vários níveis, e mostra que o tema é ainda polêmico e tenso, mesmo cinquenta anos após os eventos. Assim, não se pôde fazer nenhuma pesquisa oral com antigos membros ou simpatizantes do grupo. Alguns atores secundários ainda vivos foram encontrados, mas não foi possível entrevistá-los, uns porque estavam muito longe, outros porque eram difíceis de serem localizados. Foi possível entrevistar unicamente a madre Marie-Claire Robineau - que conhecia muito bem Victor

${ }^{2}$ Sobre o cardeal Siri, deve-se ainda mencionar as seguintes obras: LAI (1993); DoLDI ( 2006); GHEDA (2009); SPIAZZI (1990). 
Alain Berto, teólogo e amigo de Mons. Lefebvre - e o padre Jay - que era superior do Seminário de Clermont à época em que o Mons. Pierre de la Chanonie era bispo de tal diocese. Todavia, o padre Jay não chegou a fazer parte do Coetus e nem colaborou com o grupo. Ele pôde simplesmente, no entanto, falar de seu antigo bispo e de sua personalidade, bem como de sua orientação teológica.

Outra dificuldade se apresentou: a dispersão dos arquivos; como os bispos do grupo vinham de várias partes do mundo, seria lógico que seus documentos também viessem dos mais diversos lugares. Além do mais, tais documentos foram redigidos em diferentes línguas. O primeiro lugar no qual se buscou informações foi a abadia Saint- Pierre de Solesmes, já que o superior desta congregação, D. Prou, foi um membro importante do CIP, mas ainda devido ao fato de vários teólogos desta congregação terem colaborado com o grupo. Nos arquivos desta abadia pôde-se consultar os arquivos "Concile Vatican II" e uma parte dos arquivos "Dom Jean Prou", "Dom Georges Frénaud" e "Dom Paul Nau". Alguns documentos interessantes foram encontrados, mas os arquivos da abadia de deixam a desejar quando o assunto é o Concílio.

Ainda na França, consultou-se o centro de Arquivos da "Université Catholique de l'Ouest", com a esperança de descobrir alguns documentos que fizessem referência a Mons. Henri Lusseau, que colaborou com o grupo durante as intercessões. Neste caso igualmente, os arquivos revelaram-se extremamente lacunares: documentos necessários à reconstrução de seu percurso foram localizados, mas nada que pudesse efetivamente demonstrar sua participação nas atividades do CIP3. Foi feita ainda uma tentativa de busca de seus arquivos pessoais, porém sem sucesso ${ }^{4}$. Os resultados da busca nos arquivos que faziam referência ao Mons. Pierre de la Chanonie - os arquivos diocesanos de ClermontFerrand - foram semelhantes. Nada que fizesse referência ao CIP foi encontrado.

\footnotetext{
${ }^{3}$ Arquivos da "Université Catholique de I'Ouest" (AUCO), Série G (corpo docente da faculdade de teologia), lombada 2G7 : Mons. Lusseau.

${ }^{4}$ Correspondência do autor com um membro da família.
} 
Finalmente, o único arquivo francês realmente interessante é o do abade VictorAlain Berto - peritus de Mons. Lefebvre - localizado no mosteiro dos Dominicanos do Espirito Santo (Nantes). O presente autor teve acesso a uma correspondência muito prolífica, bem como a um grande número de documentos interessantes. Sem os documentos do Padre Berto, não se poderia chegar a certas conclusões.

Os arquivos conciliares de Mons. Marcel Lebebvre no Seminário d'Écone (Suíça) demonstraram-se igualmente interessantes. A consulta dos arquivos em questão propiciou a descoberta de documentos preciosos sobre o pré-Concílio e sobre o próprio Concílio, correspondências, documentos originais do grupo, listas parciais dos membros etc.

$\mathrm{Na}$ Itália, alguns documentos interessantes também foram repertoriados. Em Roma, Pontifícia Universidade de Latrão, pode-se consultar uma parte do "arquivo Piolanti". Sua correspondência ajudou a estabelecer vários vínculos préconciliares entre personagens chaves do CIP. Obteve-se ainda acesso ao "Arquivos Concilio Vaticano II", do Archivio Segreto Vaticano; a consulta do arquivo em questão demonstrou-se frutuosa, já que se pôde examinar mais de trinta caixas de arquivos, que forneceram informações sobre a história do CIP que não poderiam ser encontradas em outro lugar. Foi possível, ainda na Itália, recorrer à Fondazione per le scienze religiose Giovanni XXIII (Bolonha), onde consultou-se uma cópia dos arquivos Carli, Siri e Proença Sigaud. Em relação ao último, o professor Rodrigo Coppe Caldeira disponibilizou generosamente uma copia digital dos arquivos "Geraldo De Proença Sigaud" que se encontram nos arquivos da arquidiocese de Diamantina.

No Canadá, tivemos acesso aos documentos de Mons. Georges Cabana, no Service des Archives de l'Archidiocèse de Sherbrooke, onde foi possível encontrar alguns documentos que permitiram precisar seu lugar no seio do grupo. Deve-se, por fim, mencionar o Center for the Study of the Second Vatican Council da 
Katholieke Universiteit Leuven (Bélgica) onde alguns documentos foram consultados.

Tentou-se ainda ter acesso a outras fontes, mas sem sucesso. Foi o caso, por exemplo, no Brasil, dos arquivos de Mons. de Castro Mayer. O autor do presente artigo escreveu à sociedade que o bispo fundou, União São João Maria Vianney5, mas nunca obteve resposta. Analogamente, não se obteve sucesso no contato com a Sociedade Brasileira de Defesa da Tradição, família e Propriedade (TFP), cujos membros distribuíam documentos do CIP (TISSIER DE MALLERAIS, 2002, p. 309): eles sugeriram a leitura do livro de Roberto de Mattei (1997), que não chega efetivamente a trazer muitas informações sobre o papel da TFP no concilio nem de sua implicação no seio do Coetus. Foram feitas ainda pesquisas sobre os Chevaliers de Notre-Dame que, segundo certos indícios, teriam ajudado o grupo dirigido por Mons. Lefebvre em Roma. O presente autor entrou em contato com certos membros da Ordem. Segundo eles, os Cavaleiros não teriam colaborado diretamente com o CIP. Dom Lafond, o fundador, estava disposto a responder às questões que podiam eventualmente lhe ser feitas. Infelizmente, ele morreu antes de poder ser contactado. Foi ainda feita uma tentativa de contato com os clarentianos, visando a consulta dos arquivos do padre Torrès Llorente - secretario do cardeal Larraona, que ajudou o CIP em Roma - mas sem sucesso. Situação semelhante se reproduziu nos augustinianos no tocante aos arquivos do padre Rubio: os Arquivos gerais da Ordem contêm somente documentos oficiais. As tentativas feitas com o intuito de se encontrar documentos de cunho pessoal não obtiveram êxito. Enfim, deve-se mencionar que o presente autor foi a Nantes, ao Centre des Archives Diplomatiques de Nantes (CADN): há documentos sobre o concilio, mas nada concernente ao CIP.

\footnotetext{
${ }^{5}$ Após sua reintegração à plena comunhão jurídica com Roma, em 2002, tal instituição ganhou o nome de Administração apostólica pessoal São João Maria Vianney.
} 
Fora estes arquivos, existiam algumas fontes impressas disponíveis. Além das Acta et Documenta Concilio Oecumenico Vaticano II apparando ${ }^{6}$, das Acta synodalia Sacrosancti Concilii Oecumenici Vaticani II7 e do Anuário pontifício (1959 a 1965), pôde-se ainda tirar proveito de algumas crônicas e jornais conciliares. Entre estes, o mais importante foi sem duvida a obra de Ralph M. Wiltgen, Le Rhin se jette dans le Tibre (1974), já o autor transmite o pensamento do CIP via sua agência de notícias, estando bem informado em relação documentos e à ação do grupo. Utilizou-se ainda o diário conciliar de Yves Congar (2002), as crônicas de Giovanni Caprile (1965-1969), de Henri Fesquet (1966), de René Laurentin (1962-1967), de Robert Rouquette (1968) e Antoine Wenger (1963; $1964 ; 1965 ; 1966)$.

\section{Avaliação da organização, da atividate e da estratégia do CIP}

É difícil conhecer com precisão a data de nascimento do Coetus Internationalis Patrum. Os arquivos são muito lacunosos no que diz respeito aos seus primeiros momentos, mas eles permitem ao menos vislumbrar que um primeiro "piccolo comitato" formou-se em torno de Mons. Marcel Lefebvre desde os primeiros dias do Concílio $^{8}$, tendo este se constituído de maneira progressiva no curso da primeira sessão. Ao mesmo tempo em que esse grupo em torno de Mons. Lefebvre reforçava-se, ficava cada vez mais evidente que a trajetória dada ao Concílio, pelas comissões preparatórias, estava desaparecendo para integrar uma orientação herdada dos diferentes movimentos que tinham marcado a Igreja desde

\footnotetext{
${ }^{6}$ Acta et Documenta Concilio Oecumenico Vaticano ll apparando, Città del Vaticano: Typis polyglottis vaticanis, Series I, Antepraeparatoria : Vol. I: "Acta Summi Pontificis Joannis XXIII 》, 1960 ; Vol. II : "Consilia et vota episcoporum ac praelatorum (8 tomos divididos em eras geográficas e 2 tomos de appendices, 1960-1961; Vol. III : " Proposita et monita SS. Congregationum Curiae Romanae », 1960 ; Vol. IV : "Studia et vota Universitatum et Facultatum Ecclesiasticarum et Catholicarum » (3 tomos), 1961 ; Volume d' «Indices ", 1961. Serie II, Praeparatoria : Vol. I : " Acta Summi Pontificis Ioannis XXIII ", 1964 ; Vol. II : " Acta pontificae Commissionis Centralis praeparatoriae Concilii Oecumenici Vaticani II " (4 tomos), 1965-1968; Vol. III : "Acta Comissionum et Secretariatuum praeparatorium Concilii Oecumenici Vaticani II" (2 tomos), 1969; Vol. IV: "Acta Subcommissionum Comissionis Centralis Praeparatoriae » (3 tomos), 1988, 1993, 1994.

${ }^{7}$ Acta synodalia Sacrosancti Concilii Oecumenici Vaticani II, Città del Vaticano: Typis polyglottis vaticanis, 1970-2000, 6 tomos, 35 volumes : Tomo 1, partes 1-4. Congregationes generales 1-36; Tomo 2, partes 1-6. Congregationes generales 37-79; Tomo 3, partes 18. Congregationes generales 80-127; Tomo 4, partes 1-7. Congregationes generales 128-168; Tomo 5, partes 1-3. Processus verbales, 1962-1965; Tomo 6, partess 1-4. Acta secretariae generalis, 1962-1965; Apêndices 1-2 ; Índices.

${ }^{8}$ Carta de Mons. Marcel LefEBVRE ao Cardeal William GoDfREY, Roma, 19 de outubro de 1962. Arquivos do Seminário de Écône (ASE), E02-05, 001.7
} 
o inicio do século XX. Durante a primeira sessão, formou-se então um primeiro "Grupo de Estudo", ancestral do Coetus Internationalis Patrum; tal ancestral, no entanto, não chegou a ser um grupo organizado, estruturado, com uma estratégia claramente definida. Tratava-se de um reagrupamento anônimo de padres conciliares "de orientação tradicional"9, reunidos espontaneamente para lutar contra a direção que tomava o Concílio. Era somente um grupo de pessoas desorientadas pelo rumo dos eventos, sem estratégia, em razão da evolução imprevista e imprevisível do Concílio, e que adotaram uma posição defensiva, sem os meios para articular uma defesa coerente.

As coisas evoluíram durante a primeira intersecção e a segunda sessão. É durante este período que o grupo foi criado e que se dotou de uma estrutura e de uma estratégia, sem, todavia, ser nomeado. Segundo os arquivos, a decisão de formar um grupo organizado foi tomada durante a primeira intersecção por Mons. Geraldo de Proença Sigaud e Mons. Lefebvre, que garantiu o apoio dos beneditinos de Solesmes - com os quais trabalhou nos esquemas que tinham sido enviados aos padres conciliares durante a intersecção - e de um peritus privatus, o abade Victor-Alain Berto (1989, p. 41) ${ }^{10}$. Este último tornou-se rapidamente o teólogo do grupo, assumindo, assim, um papel importantíssimo no decorrer dos eventos.

As fontes que permitem datar o nascimento oficioso do CIP - e não oficial, já que ele ainda não tinha sido nomeado e agido oficialmente na condição de grupo - aponta para a quarta-feira, dia 2 de outubro de 1963, ou seja, três dias após a abertura da segunda sessão ${ }^{11}$. Neste dia, uma primeira assembleia reuniu quinze Padres conciliares que confiaram unanimemente a presidência de associação da qual faziam parte a Mons. Lefebvre. O grupo adotou imediata e espontaneamente uma estrutura de dois níveis: um comitê diretor - que deveria planejar e organizar

\footnotetext{
${ }^{9}$ Carta de Mons. Geraldo de Proença Sigaud a Mons. Marcel LefebVre, Diamantina, 18 de abril de 1963, ASE E02-09A, 001.

${ }^{10}$ Carta do Padre Victor-Alain BerTo ao cónego MADEC, 19 de setembro de 1963, Arquivos dos Dominicanos do Espírito Santo (ADSE), fundos.

${ }^{11}$ Agenda de D. Jean Prou, quarta-feira, 2 de outubro de 1963, Arquivos da Abadia Beneditina de Solesmes (AABS).
} 
suas ações - e assembleias gerais ${ }^{12}$. Estas assembleias reuniam todas às terçasfeiras à noite os membros e simpatizantes do CIP em torno de um conferencista, que lhes falava a respeito de um tema debatido no Concílio.

O grupo constituiu-se gradualmente ao longo da sessão II. Ele foi construído, acima de tudo, sobre os alicerces das amizades e contatos préconciliares entre aqueles que viriam a ser seus membros, mas também sobre o recrutamento feito por meio de intervenções públicas. Foi dessa maneira que Mons. Carli associou-se ao CIP (WILTGEN, 1974, p. 88-89), aparentemente trazendo consigo simpatizantes ${ }^{13}$. Eis um testemunho do padre Berto sobre o nascimento do Coetus:

Ele (o grupo) não nasceu a partir de um plano idealizado por alguém; ele não nasceu de um projeto combinado entre muitos; ele não nasceu de um pacto conjurado. Ele nasceu de uma "harmonia pré-estabelecida" à leur propre insu, entre os padres conciliares, que não se conheciam antes do Concílio, mas que se identificaram uns com os outros como se se conhecessem há tempos. Restou-lhes somente o trabalho de perceber que suas visões doutrinais e pastorais eram semelhantes, como eram semelhantes seus desejos em relação aos futuros resultados do Concílio, como eram semelhantes suas apreciações em relação aos eventos e aos homens na medida em que o próprio Concílio prosseguia. A partir disso nasceriam relações mais estreitas, encontros mais frequentes. E ainda já com a segunda sessão em andamento - seja por iniciativa de um ou outro Padre, ou de um teólogo, foram feitas conferências abertas a todos, desde o Cardeal ao "especialista privado", nas quais eram bem vindas todos que se interessavam ao Concílio, não somente aos que eram favoráveis às ideias do CIP [...] De maneira igualmente espontânea à constituição do Coetus dos Padres, constituiu-se uma espécie de "Coetus Menor", formado por teólogos: amizade antes de tudo, e posterior e rapidamente, colaboração fraterna e cotidiana de acordo com as intenções do "Coetus Maior"14.

Como bem demonstra a citação acima, o CIP possuía teólogos cujo papel não deve ser negligenciado. Os dois mais importantes foram o Padre Victor-Alain

\footnotetext{
12 Processo verbal da assembleia da quinta-feira, 3 de outubro, 17h, ADSE, fundos Victor-Alain BERTO. A análise dos arquivos, no entanto, tende a demonstrar que tal assembleia ocorreu, no entanto, na quarta-feira, 2 de outubro.

${ }^{13}$ Acta Synodalia Sacrosancti Concilii Oecumenici Vaticani II (AS), II/V, 72-75.

${ }^{14}$ Carta do Padre Victor-Alain BERTo ao diretor de "Rivarol", 19 de março de 1966. ADSE, fundos Victor-Alain BERTO, dossiê "Concílio Vaticano II". O Padre BERTO tinha escrito tal carta ao diretor do jornal em questão para protestar contra uma carta do cônego LAURETIN, que havia sido publicada na edição de 17 de fevereiro de 1966.
} 
Berto e Dom Georges Frénaud ${ }^{15}$, mas outros se juntaram ao grupo de maneira mais ou menos esporádica, como os Padres Labourdette e Gagnebet, por exemplo ${ }^{16}$. O trabalho dos teólogos consistia essencialmente em estudar os esquemas, em compor notas e memórias para os bispos e distribuí-las em Roma, assim como em ajudar os Padres conciliares na elaboração de suas intervenções orais ou escritas ${ }^{17}$.

No início da sessão, o grupo não possuía nenhum meio material. No entanto, a partir do início do mês de novembro ${ }^{18}$, o grupo adquiriu um mimeógrafo que lhe permitiu divulgar suas ideias a um maior número de Padres conciliares. Materialmente desamparado ao longo da segunda sessão, o Coetus Internationalis Patrum tinha, no entanto, bons contatos, contatos esses que poderiam lhe dar a esperança de agir nos altos comandos e contornar as vias habituais: o comitê diretor poderia esperar receber o apoio do cardeal Ottaviani; por meio do cardeal Siri e, sobretudo, do cardeal Ruffini, o grupo tinha acesso ao Conselho de Presidência; por meio do Cardeal Siri e de Mons. Carli, o grupo tinha sua participação garantida na Conferência Episcopal Italiana; Mons. Carli era um veterano de Latrão, estando ainda no comando da pequena diocese de Segni, de onde vinha Mons. Felici'19.

Desde o início da sessão, os dirigentes do CIP não hesitaram em utilizar todos os meios e contatos possíveis para chegar aos seus objetivos. Assim sendo, desde os primeiros dias, eles se dirigiram diretamente ao Papa, provavelmente por intermédio do cardeal Ruffini ou do cardeal Siri, para denunciar o funcionamento do Concílio, que interferia na ação do CIP e apontava para uma possível vitória das

\footnotetext{
${ }^{15}$ Carta do Padre Victor-Alain Berto a MB, Roma, 17 de outubro de 1963. ADSE, Fundos Victor-Alain Berto, dossiê “Concílio Vaticano II".

${ }^{16}$ Carta do Padre Victor-Alain BerTo a MM, Roma, 12 de novembro de 1963. ADSE, Fundos Victor-Alain BerTo, dossiê "Concílio Vaticano II".

${ }^{17}$ Carta do Padre Victor-Alain BerTo a um dominicano do Espírito Santo (D.), Roma, 5 de outubro de 1963; Carta do Padre Victor-Alain BERTO a MB, Roma, 17 de outubro de 1963. ADSE, Fundos Victor-Alain BERTO, dossiê "Concílio Vaticano II".

${ }^{18}$ Carta do Padre Victor-Alain BERTO a um dominicano do Espírito Santo (D), Roma, 6 novembro de 1963. ADSE, Fundos Victor-Alain BERTO, dossiê "Concílio Vaticano II".

${ }^{19}$ Atualmente - devido ao presente estado da documentação - não é possível provar que Mons. Carli chegou a se beneficiar de tal contato.
} 
ideias de uma minoria. Eles propuseram, então, uma forma de proceder radicalmente diferente, mas tal demanda não surtiu efeito ${ }^{20}$.

Durante a segunda sessão, o Coetus Internationalis Patrum nasceu informalmente, portanto. Deve-se, no entanto, enfatizar que ele ainda não agia publicamente como grupo. A petição que pedia a condenação do comunismo que foi entregue ao Cardeal Cicognani em dezembro de 1963, por exemplo, foi acompanhada de uma carta assinada pelos NN.SS. de Proença Sigaud e Castro Mayer, na qual não se fazia nenhuma menção do grupo ao qual eles pertenciam²1. Situação semelhante pode ser observada nos documentos De Revelaione, De Ecclesia, e De Episcopis ac de dioecesium regimine, que o grupo tinha enviado ao Secretariado Geral do Concílio durante a intersecção ${ }^{22}$. Mesmo sem ainda ter adotado um nome, o CIP já estava relativamente bem estruturado e organizado, como o prova a existência do comitê diretor e das assembleias gerais, bem como a tática adotada pelos próprios membros do comitê diretor para contrapor os pontos que eles julgavam ambíguos: coordenar as intervenções de seus membros e fazer com que elas fossem ratificadas por outros.

A partir da segunda interseção, o CIP entrou numa segunda fase de sua história. Depois do fim da segunda sessão, reconfortado pelo discurso de Paulo VI e pela audiência que tinha tido com ele, Mons. Lefebvre decidiu continuar adiante, mobilizando assim suas tropas ${ }^{23}$. Foi assim que, durante a interseção, o grupo realizou quatro reuniões em Solesmes; tais reuniões tiveram como consequência a

\footnotetext{
${ }^{20}$ Carta do Coetus Internationalis Patrum a Paulo VI, s.d., mas no começo da segunda seção; "Ratio nova procedendi in congregationibus generalibus proposita", anexada à carta precedente, ASE, fundos Marcel LEFEBVRE, E.02.10.002. Carta de Mons. Pericle FeliCl a Mons. Marcel LefebVre, Vaticano, 11 novembro de 1963 ; Carta de Marcel LefebVRe ao cardeal RuffinI, Roma, 13 novembro de 1963, ASE, fundos Marcel LeFEBVRE, E02-10. "Colloquium primum", processo verbal da reunião do dia 6 de outubro de 1963 ; "Colloquium alterum", processo verbal da reunião da terça-feira, dia 8 de outubro de1963; "Congressus alter", processo verbal da assembleia da terça-feira, dia 8 de outubro de 1963; "Colloquium tertium", processo verbal da reunião da quinta-feira, dia 10 de outubro de 1963; "Colloquium quartum", processo verbal da reunião do sábado, dia 12 de outubro, na casa geral da Congregação do Santíssimo Salvador, ADSE, fundos Victor-Alain BERTO. Carta do Padre Victor-Alain BERTO a M.P., Roma, 13 de novembro de 1963, ADSE, fundos Victor-Alain BERTO, dossiê “Concílio Vaticano II".

${ }^{21}$ Carta de Mons. De Proença Sigaud e de Mons. De CAStro Mayer, Campos, 31 de julho de 1963, AABS, Pasta D. Prou-Vaticano II, dossiê $\mathrm{n}^{\circ} 20$.

${ }^{22}$ ASE, E02-09A, 004 ; Archivio Segreto Vaticano (ASV), Fundos Concílio Vaticano II, Pasta 762, 272 e Pasta 765, 294, fascículo 3 ; AS II/I, 647-652; AS II/IV, 851 ; AS III/III, 888-891.

${ }^{23}$ Carta de Mons. Marcel LefebVre a Mons. Pericles Felicl, Paris, 8 de fevereiro de 1964, ASE, E02-09A, 001 ; Carta de Mons. Marcel LefeBvre a D. Jean Prou, Paris, 23 de dezembro de 1963, AABS, pasta D. Prou - Vaticano II, dossiê n² 20.
} 
redação de diversos documentos, dentre eles, duas súplicas ao Papa (ROYLYSENCOURT, 2011, Tomo 4, p. 733-779). Tais súplicas, assim como uma petição pedindo a consagração do mundo ao Imaculado Coração de Maria ${ }^{24}$, que foi entregue por Mons. de Proença Sigaud diretamente a Paulo VI, demonstram que o CIP visava uma ação vinda do alto e que esperava que o romano pontífice se servisse de sua autoridade para influenciar o curso dos debates em favor do grupo.

De qualquer maneira, foi durante a segunda interseção que o grupo nasceu oficialmente. Os arquivos contém uma carta circular - datada do dia 5 de agosto e assinada pelos NN.SS. Lefebvre, de Proença Sigaud, Cabana, Silva Santiago, Lacchio e Cordeiro - anunciando um reagrupamento de Padres conciliares ligados à "tradição da Igreja”. Eles citavam como justificativa desse reagrupamento os recentes acréscimos feitos às regras do Concílio, que permitiam que Padres que pensassem de maneira semelhante pudessem se agrupar para que um deles falasse oficialmente em nome dos demais ${ }^{25}$. Tal carta pode ser considerada o primeiro ato oficial do CIP, mesmo o grupo ainda não possuindo nenhum nome, algo que só viria a surgir no início da sessão.

Outro elemento pode confirmar que o CIP havia entrado numa nova dinâmica a partir de 1964: Mons. Lefebvre e o Padre Berto chegaram a Roma alguns dias antes da abertura da terceira sessão para organizar os trabalhos ${ }^{26}$. Eles tinham viajado de carro, para poderem usufruir localmente de um meio de transporte mais eficaz que ônibus e taxis ${ }^{27}$. Ao chegarem a Roma, o superior geral da Congreção dos Padres do Espírito Santo e o Padre Berto trabalharam parar confederar os "romanos" e para deixar tudo preparado para que a ação do grupo

\footnotetext{
${ }^{24} \mathrm{AAD}$, fundos Geraldo de Proença Sigaud. Sobre a história detalhada dessa petição, ver Roy-Lysencourt (2011, Tomo 4, p. 750-758).

${ }^{25}$ Carta circular de Mons. Marcel LefeBvre, Mons. Geraldo DE Proença SIGAUd, Mons. Georges Cabana, Mons. Alfredo SILVA SANTIAGO, Mons. Secondino PETRONIO LACCHIO e Mons. Josephus CORDEIRO, 5 de agosto de 1964, ASE, fundos Marcel Lefebvre, E 02-10, 003 ; AABS,

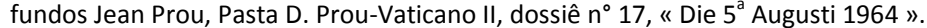

${ }^{26}$ Carta do Padre Victor-Alain BERTO a C.M., 26 de agosto de 1964. ADSE, Fundos Victor-Alain BERTO, dossier "Concílio Vaticano II".

${ }^{27}$ Carta do Padre Victor-Alain BERTO a C.M., 26 de agosto de 1964. ADSE, Fundos Victor-Alain BERTO, dossier "Concílio Vaticano II".
} 
fosse mais eficaz que nas sessões precedentes ${ }^{28}$. Contrariamente às duas primeiras sessões, o CIP começava, portanto, a terceira sessão estando organizado: Mons. Lefebvre e seu peritus tinham feito os contatos necessários para mobilizar os tradicionalistas, eles tinham um carro, um local, e a primeira reunião de trabalho estava prevista para a terça-feira seguinte à abertura oficial da sessão.

Semelhantemente ao que havia acontecido durante a segunda sessão, o CIP continuou a realizar as reuniões-conferências das terças-feiras à noite29. Outra iniciativa, que aparentemente não fez tanto sucesso quanto a citada acima, porém, consistiu na criação de um secretariado perto da Praça de São Pedro ${ }^{30}$. Os Padres conciliares podiam ir ao tal secretariado para buscar documentos produzidos pelos membros do grupo. É difícil, no entanto, avaliar com precisão o impacto desse secretariado, que deve ter sido mínimo, provavelmente, segundo o que se pode deduzir a partir dos arquivos. No entanto, a estratégia privilegiada pelo grupo para essa sesão foi a produção e distribuição de modi $3^{1}$. Eles eram preparados na residência do cardeal Larraona, que havia colocado a disposição do grupo seu material de policópia e seus dois secretários ${ }^{2}$. O trabalho de então - ao menos o realizado pelos teólogos - era completamente diferente do realizado no ano anterior.

\footnotetext{
${ }^{28}$ Carta do Padre Victor-Alain BeRTo aos Dominicanos do Espírito Santo, Roma, 8 de setembro de 1964 ; Carta do Padre Victor-Alain Berto a B., 10 de setembro de 1964 ; Carta do Padre Victor-Alain Berto aos Dominicanos do Espírito Santo, Roma, 12 de setembro de1964 ; Carta do Padre Victor-Alain BerTo ao C.M., 12 de setembro de 1964 ; Carta do Padre Victor-Alain BerTo a M., 13 de setembro de1964. ADSE, Fundos Victor-Alain BERTO, dossiê "Concílio Vaticano II".

${ }^{29}$ Carta do Padre Victor-Alain BeRTO a C.M., Roma, 12 de setembro de1964 ; Carta do Padre Victor-Alain BerTo a uma Dominicana do Espírito Santo (Jn), Roma, 14 de setembro de 1964, ADSE, Fundos Victor-Alain BERTO, dossiê "Concílio Vaticano II". Carta circular de Mons. Marcel LefEBVRE aos presidents das conferências episcopais, Roma, 21 de setembro de 1964, ASE, fundos Marcel Lefebvre, E.02.10.004 ; Jornal de Mons. Geraldo de Proença Sigaud, Arquivos da Arqudiocese de Diamantina (AAD), fundos Geraldo de Proença Sigaud ; Trato do 2 de outubro de 1964, AAD, fundos Geraldo de Proença Sigaud ; Trato do 6 de outubro de 1964, ASE, fundos Marcel Lefebvre, E.02.10.004 ; Trato do 16 de outubro, AAD, fundos Geraldo de Proença Sigaud ; Trato do 21 de outubro, AAD, fundos Geraldo de Proença Sigaud, ASE, fundos Marcel Lefebvre, E.02.10.004; Trato do 21 de outubro de 1964, ASE, fundos Marcel Lefebvre, E.02.10.004 ; Trato do 27 de outubro 1964, ASE, fundos Marcel Lefebvre, E.02.10.004, AAD, fundos Geraldo de Proença Sigaud.

${ }^{30}$ Trato do 2 de outubro de 1964, AAD, fundos Geraldo de Proença Sigaud ; Carta do Padre Victor-Alain BERTO a A., 23 de setembro de 1964; Carta do Padre Victor-Alain BERTO a D., 23 de setembro de 1964, ADSE, Fundos Victor-Alain BerTo, dossiê "Concílio Vaticano II".

${ }^{31}$ Carta do Padre Victor-Alain BERTO a D., 12 de outubro de 1964; Carta do Padre Victor-Alain BeRTO a J.L., 12 de outubro de 1964, ADSE, Fundos Victor-Alain BERTO, dossiê "Concílio Vaticano II".

${ }^{32}$ Carta do Padre Victor-Alain BERTO a B., 25 de setembro de1964; Carta do Padre Victor-Alain BERTO a M.P., 26 de setembro de 1964; Carta do Padre Victor-Alain Berto a D., 3 de outubro de 1964; Carta do Padre Victor-Alain BERTO a M., 5 de outubro de 1964; Carta do Padre Victor-Alain BerTo a J.L., 12 de outubro de1964; Carta do Padre Victor-Alain BERTo aos Dominicanos do Espírito Santo, 18 de outubro de 1964; carta do Padre Victor-Alain BERTO a P., 5 de outubro de 1964; Carta do Padre Victor-Alain BERTO A J.L., 12 de outubro de 1964; Carta do Padre Victor-Alain BERTO a Cl., 9 de outubro de 1964; Carta do Padre Victor-Alain BERTO a J.L., 12 de outubro de 1964; Carta do Padre Victor-Alain BERTO a C.M., 30 de outubro de 1964. ADSE, Fundos Victor-Alain BerTo, dossiê "Concílio Vaticano II".
} 
Se o Coetus Internationalis Patrum manteve sua estrutura e organização anteriormente adotados durante a segunda sessão, a tática e as condições de trabalho não foram as mesmas. Os dirigentes do CIP adaptaram-se à conjuntura particular dessa sessão e produziram um fluxo quase que ininterrupto de modi, esperando assim modificar in extremis as passagens dos esquemas que eles julgavam ambíguos ou contrários à tradição da Igreja. O grupo, que tinha então mais recursos, além do apoio explícito de vários cardeais, não estava mais somente na defensiva. Sua tática passou a ser mais ofensiva e sua estratégia bem definida. Tal estratégia poder-se-ia resumir na seguinte fórmula, frequentemente utilizada por Victor-Alain Berto a partir de 17 de setembro: "federar os romanos" 33.

A terceira intersecção e a quarta sessão foram bastante semelhantes à segunda intersecção e à terceira sessão no tocante às estratégias de ação e de organização. Os arquivos que dizem respeito a essa sessão são mais raros que os relativos às sessões precedentes, o que torna mais difícil esclarecer certos aspectos. Sabe-se, entretanto, que o CIP manteve reuniões, dessa vez em Solesmes34 e em Roma35, enviando estudos sobre os esquemas ao Secretariado Geral do Concílio. Durante a segunda sessão, o grupo distribuiu aos Padres conciliares os modi, instruções de votos e cartas circulares; o grupo ainda endereçou cartas ao Papa, ao Secretariado geral e aos moderadores. Por fim, lançou uma petição. Atualmente, não é possível afirmar se as reuniões das terças-feiras à noite continuaram, já que os arquivos disponíveis não conservaram nenhum traço sobre essa questão; uma carta do Padre Berto, no entanto, deixa a entender que tais reuniões estavam previstas e deveriam continuar acontecendo36. Aparentemente, portanto, não

\footnotetext{
${ }^{33}$ Carta do Padre Victor-Alain Berto aos Dominicanos do Espírito Santo, 17 de setembro de 1964, ADSE, Fundos Victor-Alain BeRTo, dossiê "Concílio Vaticano II".

${ }^{34}$ Carta de Mons. Marcel Lefebvre a D. Jean Prou, Paris, 22 de junho de 1965; carta de Mons. Marcel LefebVre a D. Jean Prou, Paris, 10 de julho de 1965, AABS, pasta D. Prou - Vaticano II, dossiê n²0; Agenda de D. Jean Prou, quinta-feira, 15 de julho de 1965; Agenda de D. Prou, quarta-feira, 21 de julho de 1965, AABS ; carta de Mons. Marcel LefEBVRE ao Padre Victor-Alain BerTo, Paris, 18 de agosto de 1965, ADSE, fundos Victor-Alain Berto, dossiê "Concílio Vaticano II".

${ }^{35}$ Carta de Mons. Marcel LefebVre ao Padre Victor-Alain Berto, Roma, 25 de julho de 1965, ADSE, fundos Victor-Alain Berto, dossiê "Concílio Vaticano II".

${ }^{36}$ Carta do Padre Victor-Alain BerTo ao cônego MADEC, 9 de setembro de 1965, ADSE, fundos Victor-Alain Berto, dossiê "Concílio Vaticano II".
} 
houve diferença substancial entre a quarta sessão e a sessão precedente no que diz respeito à estratégia adotada pelo CIP. Por outro lado, o grupo tinha perdido um de seus principais atores, o Padre Victor-Alain Berto, que foi vítima de uma trombose de retina pouco tempo após o fechamento da terceira sessão, não podendo, portanto, trabalhar com o grupo a Roma37. Durante a intersecção, o CIP foi ainda desautorizado pelo Secretário de Estado ${ }^{8}$, mas os membros do grupo decidiram não levar em conta tal desautorização, continuando a se opor a ideias que seus membros julgavam inaceitáveis nos esquemas conciliares, servindo-se dos mesmos meios de antes. O grupo evitou, todavia, ao menos temporariamente, utilizar o nome que lhe havia sido dado durante a terceira sessão39.

A tática evoluiu, portanto, ao longo das sessões e o grupo se adaptou à progressão dos trabalhos na aula. Assim, a partir da terceira sessão, quando os Padres conciliares foram chamados a votar em diversos esquemas, o CIP preparou e distribuiu vários modi.Durante as intersecções, o meio privilegiados pelo Coetus era a produção de estudos sobre os esquemas e intervenções junto ao Papa. Ambas as táticas não foram desprezadas durante as sessões, mas foram acrescentadas às intervenções na aula, por vezes coordenadas, à distribuição de modi, às conferências das terças-feiras à tarde e ao secretariado situado próximo à Praça de São Pedro para difundir o pensamento do grupo em meio aos Padres Conciliares. A tudo isso, deve-se ainda acrescentar as petições, tendo três sido as mais importantes: a primeira pedindo a consagração do mundo ao Coração Imaculado de Maria, as duas outras pedindo a condenação explícita do comunismo. As diferentes estratégias adotadas pelo CIP demonstram que seus dirigentes haviam entendido muito bem a preocupação conciliar em chegar a um consenso. Assim sendo, o que o grupo - sendo minoria - procurou acima de tudo foi evitar a

\footnotetext{
${ }^{37}$ Carta do Padre Victor-Alain BerTo a Mons. Luigi CARLI, Notre-Dame de Joie, 29 de junho de 1965, no Nicla BuonASORTE, "Per la "pura, piena, integra fede cattolica" : il p. Victor Alain BERTO al concilio Vatican II", Cristianesimo nella storia 22, 2001, p. 140 ; carta do Padre Victor-Alain BERTO ao Cardeal Alfredo OTTAVIANI, 24 de janeiro de 1965, ASV, fundos Concílio Vaticano II, Cartão 756, dossiê 243 ; carta de Mons. Marcel Lefebvre ao Padre Victor-Alain Berto, Roma, 24 de setembro de 1965, ADSE, fundos Victor-Alain Berto, dossiê "Concílio Vaticano II".

${ }^{38}$ Carta do Cardeal Amleto CICognANI a Mons. Luici CARLI, Cidade do Vaticano, 11 de agosto de 1965, AS VI/IV, 140-141; AAD, fundos Geraldo de Proença Sigaud.

${ }^{39}$ Por exemplo, a carta do grupo aos moderadores, Roma, 18 de setembro de 1965, AS V/III, 360-362, ou "Petitio quorundam Patrum", Roma, 21 de setembro de 1965, AS V/III, 372.
} 
unanimidade moral. O Padre Berto não estava usando uma figura de linguagem quando falava em "federar os romanos". No entanto, os arquivos não permitem vislumbrar qualquer tipo de estratégia de aliança do Coetus com outro grupo. O CIP, segundo o testemunho do Padre Berto, não possuía nenhuma estratégia para manter seus próprios simpatizantes:

[O] "Coetus" nunca chegou a ser aquilo que em francês chamamos de "groupe"40; nada de inscrição, nada de estabilidade ou sequer estatutos, e muito menos qualquer tipo de engajamento ou obrigação de qualquer espécie. Nem mesmo um "chefe" para comandar tropas, pois nem mesmo tropas para ser comandadas existiam. Toda liberdade de vir ou de não vir, de retornar ou de não retornar, de aceitar ou não aceitar as alterações propostas pelos teólogos do "Coetus"; nenhuma necessidade de se dar satisfação sobre os votos que cada um havia votado em sua própria alma e consciência. Sob esses critérios, os membros de um Concílio ecumênico são iguais entre si; assim, pois, eram os membros do Coetus, iguais entre si. O Coetus não precisava de uma "cabeça", já que nunca tinha sido um "corpo"41.

\section{O Impacto do CIP sobre os esquemas do Concílio}

Os membros e simpatizantes do CIP pronunciaram-se sobre cada um dos dezesseis textos conciliares promulgados. Eles tinham críticas a serem feitas sobre cada um deles, mas nem todas com o mesmo teor. Certos esquemas não tinham uma grande importância doutrinal, o que fez com que o CIP dirigisse-lhes apenas alguns julgamentos e reprimendas em relação a alguns detalhes. Foi o caso no tocante aos esquemas sobre os meios de comunicação social (Inter Mirifica), sobre o apostolado dos leigos (Apostolicam Actuositatem), sobre as Igrejas Católicas Orientais (Orientalium Ecclesiarum), e sobre a educação católica (Gravissimum Educationis).

\footnotetext{
${ }^{40}$ Também em português, "grupo". N.T.

${ }^{41}$ Carta do Padre Victor-Alain BeRTo ao Diretor de "Rivarol", 19 de março de 1966, ADSE, fundo Victor-Alain Berto, dossiê "Concílio Vaticano II".
} 
Outros esquemas apresentavam questões doutrinais mais significativas, mas os membros do Coetus mais uma vez não se pronunciaram de maneira expressiva, talvez por falta de tempo, já que era necessário priorizar certos combates. Foi o caso dos esquemas sobre o ministério e a vida dos sacerdotes (Presbyterorum Ordinis), sobre a renovação da vida religiosa (Perfectae Caritatis), sobre a formação dos sacerdotes (Optatam Totius), e sobre a atividade missionária da Igreja (Ad Gentes). O Fato de eles não terem se mobilizado contra esses textos não significa que eles estivessem satisfeitos - testemunhos que são citados na tese do presente autor demonstram que eles desejavam que tais esquemas tivessem sido redigidos com outro espírito, tendo, alguns deles sido, inclusive, objeto de intervenções bastante virulentas - mas sim que eles não tinham queixas doutrinais de grande importância contra tais escritos.

Em relação a outros esquemas, a oposição dos membros e simpatizantes do CIP foi virulenta. Dentre tais oposições, devem-se considerar, com variável importância, os esquemas sobre a liturgia (Sacrosanctum Concilium), sobre o ecumenismo (Unitatis Redintegratio), sobre a responsabilidade pastoral dos bispos (Christus Dominus), sobre a Igreja (Lumen Gentium), sobre a Revelação (Dei Verbum), sobre a liberdade religiosa (Dignitatis Humanae), sobre as religiões não cristãs (Nostra Aetate) e sobre as relações da Igreja com o mundo (Gaundium et Spes). A oposição em relação a todos esses esquemas - dos quais três dependiam do Secretariado para a Unidade dos Cristãos - foi consideravel, tendo os membros do CIP condenado a maior parte deles em bloco, já que eles reprovavam a orientação teológica na qual tais documentos tinham sido redigidos, e também porque acreditavam que os ensinamentos vinculados por tais esquemas se opunham à doutrina tradicional da Igreja.

Nessa parte, avaliar-se-á o impacto do Coetus sobre os esquemas contra os quais ele próprio se opôs com mais afinco; deve-se, no entanto, especificar que não há espaço neste artigo para a discussão de detalhes. O presente autor procurará, todavia, enfatizar os pontos mais importantes da oposição feita pelos membros e 
simpatizantes do CIP em relação aos esquemas do Concílio.

Em relação ao esquema sobre a liturgia, debatido somente durante a primeira sessão, os futuros membros e simpatizantes do CIP - que temiam que as modificações litúrgicas pudessem alterar a unidade da fé - opuseram-se particularmente à introdução das línguas vernáculas (na própria liturgia e também no ofício divino), à concessão de competências litúrgicas às conferências episcopais, à comunhão nas duas espécies, à concelebração (menos Dom Prou) a ainda às mudanças referentes aos sacramentos, de forma particular a extremaunção. Tais oposições, no entanto, não foram acatadas pela Comissão litúrgica, e o esquema promulgado tomou um rumo diferente do desejado pelo Coetus: o uso de línguas vernáculas foi estendido, as competências das conferências episcopais ampliadas, a comunhão nas duas espécies e concelebração aceitas, e a extremaunção transformada em sacramento dos doentes.

No tocante ao esquema sobre o ecumenismo, os membros do Coetus fizeram valer a máxima segundo a qual a Igreja Católica Romana, sob a autoridade do Soberano Pontífice, é a única via ordinária de salvação e que, consequentemente, o ecumenismo só poderia ser concebido visando o retorno dos cristãos separados da própria Igreja. Eles, portanto, reprovavam principalmente o fato de o esquema fomentar um falso irenismo, atenuar as distinções entre as Igrejas, conceder meios demais de salvação fora da Igreja Católica, de diluir o primado pontifício - ao não apresentar o Papa como única fonte de unidade - e, por fim, reconhecer que o Espírito Santo pudesse agir também nas comunidades não católicas. Os princípios defendidos pelos membros do CIP nesse debate foram principalmente a unidade e unicidade da Igreja, fundada em Pedro, e a necessidade absoluta de a Igreja, em nome da salvação, expor a fé católica clara e integralmente, sem falso irenismo. Para o Coetus, era, pois, absolutamente inadmissível e inconcebível que a Igreja pudesse se inserir e encontrar seu lugar em meio ao movimento ecumênico nascido no início do século XX. No entanto, o esquema não foi modificado à luz do 
que foi pedido pelo grupo, e os modi depositados pelo Coetus não foram bem acolhidos pela Comissão. Pode-se afirmar, portanto, que o CIP não conseguiu mudar a perspectiva teológica e o espírito segundo o qual o esquema tinha sido composto. Contudo, não se pode declarar que o grupo não teve nenhum impacto sobre o esquema. Sem a oposição pugnaz do Coetus, Paulo VI teria submetido emendas no último minuto, com o objetivo de fomentar a unanimidade? Talvez não.

O cenário foi mais ou menos o mesmo no tocante ao esquema sobre a carga pastoral dos bispos. Os membros do CIP consideravam que o conteúdo de certas partes do esquema em questão era contrário à doutrina da Igreja. Eles defenderam o primado absoluto do Papa e sua total liberdade no exercício de seu poder, a unidade do governo diocesano, e, sobretudo, eles se posicionaram contra a noção de colegialidade, devido basicamente a duas razões: eles acreditavam que tal noção não tinha fundamento teológico, jurídico e histórico e que ela arriscava reduzir tanto o poder papal quanto o episcopal. Mesmo o sentido geral do esquema não tendo sido modificado, a energia empregada pelo Coetus teve certamente um impacto direto na redação do texto final. Por exemplo, diante da divisão no tocante à constituição de um sínodo de bispos em torno do Papa para o governo da Igreja universal, Paulo VI retirou a questão do Concílio e agiu motu próprio (na ocasião do $1^{\mathrm{o}}$ dia da quarta sessão), constituindo um sínodo - consultivo - sem esperar o julgamento definitivo dos Padres. Se ele tomou tal atitude, foi devido à sua maneira de pensar, mas também, provavelmente, para tentar organizar a minoria, minoria essa que tinha no CIP seu principal representante.

O esquema sobre a Igreja - não o primeiro, mas o que resultou da "segunda preparação" - foi um dos que mais mobilizaram o Coetus Internationalis Patrum. Seus membros estimavam que o esquema era ruim, que seu espírito era execrável, que ele era equivocado e que ele adogava em favor de uma nova doutrina. Eles se levantaram contra certas expressões que julgaram ambíguas e defenderam o caráter hierárquico e monárquico da Igreja; mas o ponto contra o qual 
concentraram suas forças foi a noção de colegialidade episcopal. Eles afirmaram que o Papa era o único chefe da Igreja, e que a plenitude do poder residia somente em sua pessoa. Durante a segunda sessão, eles sofreram uma grande derrota com o voto do dia 30 de outubro, no qual a assembleia acatou o princípio da colegialidade. Mas eles não desistiram, redobrando o ardor na batalha durante a segunda intersecção e a terceira sessão. O insucesso do CIP durou até os últimos momentos, já que os modi que seus membros tinham distribuído sobre o esquema foram descartados pela Comissão. No entanto, um evento fortuito mudou o curso das coisas; Paulo VI pediu, no último minuto, que se inserisse uma Nota explicativa praevia para explicitar como se deveria interpretar o esquema. O CIP talvez não tenha participado direta e originalmente da redação desse texto, mas o fato de ele nunca ter desistido e ter continuado protestando vigorosamente contra a rejeição de seus modi provavelmente incitou o Papa a impor tal nota. Para a maioria, foi uma derrota. Para o CIP, foi uma vitória in extremis, mas um meiosucesso de qualquer modo: a nota tornava o texto aceitável para o CIP, como escreveu o Padre Berto ãs mas religiosas: "Se tivesse sido feito por nós, o texto teria tido outra letra e, sobretudo outro espírito; da maneira como ficou e com as explicações que o Santo Padre deu ontem, ele ficou aceitável42”. Dois anos mais tarde, em 1966, ele escreveu a um confrade:

Da maneira como ele ficou, independentemente da "Nota explicativa praevia", o texto [da Constituição sobre a Igreja] é aceitável e poderia ser votado, mesmo a contragosto, pelos Padres mais atrelados à romanidade! [...] O Papa falando ex cathedra, ou o Concílio, não podem definir uma heresia, ponto final. O Espírito Santo não se engajou em fazer de todos os concílios "grandes" concílios. Os teólogos do séc. XXI verão melhor que nós que o Vaticano II não foi um "grande" Concílio. Quanto à Nota explicativa praevia, não se pode deixar de repetir que [...] seu objetivo não era remover da Constituição o que nela estava contido, mas de impedir que se inserisse o que nela não estava contido43.

\footnotetext{
${ }^{42}$ Carta do Padre Victor-Alain BERTo aos dominicanos do Santo Espírito, Roma, 17 de novembro de 1964. ADSE, Fundos Victor-Alain BERTO, dossiê "Concílio Vaticano II".

${ }^{43}$ Carta do Padre Victor-Alain Berto ao Padre J. CURTRILly, 23 de dezembro de 1966, ADSE, fundos Victor-Alain Berto, dossiê "Concílio Vaticano II".
} 
Em relação ao De Ecclesia, deve-se igualmente considerar a questão da redução do esquema sobre a santíssima Virgem no seio da Igreja. O Coetus havia lutado com afinco contra isso, mas uma pequena maioria dos Padres acabou tomando a decisão contrária no dia 29 de outubro de 1963. Tal derrota foi, no entanto, atenuada ao longo da última semana da última sessão, quando Paulo VI, num ato litúrgico, venerou a Virgem Maria como mãe da Igreja.

O esquema sobre a Revelação foi outro contra o qual o CIP lutou de maneira acintosa. As questões que mais preocupavam os membros e simpatizantes do Coetus eram a questão da relação Tradição, Escrituras e Magistério, a inspiração das Escrituras e historicidade dos Evangelhos. O texto, no entanto, nunca chegou a ser modificado levando em consideração as demandas do Coetus, apesar das intervenções orais e das animadversiones scriptae de seus membros, apesar das observações críticas enviadas pelo grupo durante a terceira intersecção e ainda, apesar dos modi depositados pelo próprio CIP, dos quais apenas alguns poucos foram aceitos.

O Coetus gastou muita energia para lutar contra o esquema sobre as relações da Igreja com o mundo. Os membros do grupo estimavam que o esquema estava repleto de erros, que era ambíguo e contraditório e que se opunha à doutrina tradicional da Igreja. Eles opuseram-se ao documento até o fim: na tentativa de influenciar os votos para a primeira parte, eles distribuíram modi. Em relação à segunda parte, eles encorajaram os Padres conciliares a votar non placet em todos os escrutínios. Depois de ter recebido o texto revisado e o expressio modorum, não tendo conseguido modificar substancialmente o esquema, o CIP dirigiu-se aos Padres conciliares por meio de uma carta circular, pedindo-lhes que votassem non placet. O CIP, no entanto, não foi capaz de impedir a unanimidade moral. Todavia, de modo semelhante aos outros esquemas, o Coetus conseguiu acrescentar certos incisos, modificar certas proposições e a suavizar certas opiniões. 
O CIP teria ainda apreciado que o Concílio condenasse explicitamente o comunismo; e para os membros do CIP, tal condenação deveria se concretizar no esquema XIII. Duas petições e outras medidas, no entanto, conseguiram apenas inserir uma nota de rodapé nomeando os documentos pontificais nos quais a ideologia em questão era reprovada. Tratava-se de mais um fracasso importante do CIP, que tinha pedido a condenação explícita e formal do comunismo.

Os membros e simpatizantes do Coetus que se pronunciaram, seja por escrito ou oralmente, a respeito do esquema que abordava a questão das religiões não cristãs e os judeus foi reduzido. Esse silêncio parcial, no entanto, não significava que eles aprovassem o conteúdo do esquema. Durante a última sessão, o CIP distribuiu uma circular contra tal texto, convidando os Padres a votarem non placet em quase todas as votações parciais e no voto de conjunto. Tal documento demonstra que o grupo repudiava totalmente o trabalho do Secretariado. Para o CIP, o esquema atenuava fortemente as enormes diferenças que separavam a Igreja das outras religiões ao ponto de ser perigoso, arriscando a atrasar a conversão dos pagãos. No entanto, essa oposição não gerou resultados. O CIP não conseguiu impedir a unanimidade moral e o texto foi promulgado com os princípios que seus próprios membros atacaram.

O resultado foi semelhante no caso do esquema sobre a liberdade religiosa, com a diferença de que os membros e simpatizantes do Coetus fizeram intervenções orais consideráveis, além das numerosas ações do CIP como grupo, notavelmente durante a terceira intersecção e a quarta sessão. O Coetus protestou vigorosamente contra todas as versões desse esquema, desde a primeira a sexta. Ao lado da luta contra a colegialidade dos bispos, a luta contra a liberdade religiosa foi a mais importante do CIP, aquela na qual seus membros colocaram todas as suas forças e energias, já que, grosso modo, eles julgavam tal esquema inaceitável, radicalmente contrário à doutrina tradicional e ao Magistério dos Papas, construído segundo o desejo e pensamento de homens modernos, e não segundo o 
pensamento permanente da Igreja. No entanto, apesar da opinião rígida e de toda a energia gasta contra o esquema até o último momento por meio de intervenções orais e escritas de seus membros (cartas e requisições dirigidas a Paulo VI, aos Moderadores, ao Secretariado Geral) além das circulares gerais pedindo aos Padres Conciliares para votar non placet, o Coetus não conseguiu mudar o espírito no qual o esquema em questão foi redigido.

Concluindo, pode-se considerar que, de maneira geral, o Coetus Internationalis Patrum não foi capaz de mudar a perspectiva nem o espírito teológico nos quais os textos que eles combateram foram redigidos. No entanto, sua oposição gerou o abrandamento de várias afirmações, e, no tocante a alguns detalhes, o CIP conseguiu reformular certas frases, mudar algumas proposições ou atenuar certas expressões. Alguns desses textos do Concílio são documentos de compromisso que não seriam hoje o que são se o Coetus não tivesse - por meio de sua oposição incessante e minuciosa - conseguido modificar certas passagens. Eis o que Mons. Lefebvre disse sobre isso em 1987, fazendo um panorama da ação do CIP e seu impacto sobre os textos conciliares:

É certo que com os 250 Padres conciliares do Coetus, nós tentamos, por meio de tudo que tínhamos a nossa disposição, impedir os erros liberais de se expressarem nos textos do Concílio, o que nos permitiu de certa maneira limitar os estragos, mudar algumas afirmações inexatas ou tendenciosas, acrescentar outras frases para retificar uma ou outra proposição tendenciosa, uma expressão ambígua. Mas eu devo confessar que nós não conseguimos purificar o Concílio do espírito liberal e modernista que impregnava a maior parte dos esquemas. Os redatores eram, de fato, os especialistas e os Padres contaminados com esse espírito. Ora, o que se pode fazer quando um documento é, em seu conjunto, redigido com um falso espírito? É praticamente impossível expurgá-lo de tal espírito; seria necessário recompô-lo completamente para lhe dar um espírito católico. O que nós conseguimos fazer foi, por meio dos modi que apresentamos, acrescentar incisos nos esquemas, e isso se vê muito bem: basta comparar o primeiro esquema sobre a liberdade religiosa com o quinto esquema que foi redigido - pois esse documento foi cinco vezes rejeitado e voltou à cena cinco vezes - para ver que nós conseguimos atenuar o subjetivismo que infectava as primeiras redações. De modo semelhante, no tocante a Gaudium et spes, vê-se muito bem os parágrafos que foram acrescentados sob nossa influência, e que lá estão, poder-se-ia dizer, como remendos novos numa veste velha: não combinam; a lógica da redação primitiva não existe mais; os acréscimos feitos para atenuar ou contrabalancear as afirmações liberais ficam lá como corpos estranhos (LEFEBVRE, 1987, p. 167-168). 
Tal declaração de Mons. Lefebvre corrobora com as conclusões do presente artigo. Se o Coetus não conseguiu mudar a orientação geral da redação dos textos, ele ao menos foi capaz de atenuar certas afirmações e inserir alguns incisos, como a tese do presente autor demonstrou ao tratar dos modi sobre cada um dos esquemas e das respostas das comissões conciliares. O impacto do CIP foi, pois, real. Se os textos não têm o tom que seus membros desejaram - longe disso - eles ao menos ficaram marcado pela oposição do grupo.

\section{Conclusão}

Na tese realizada pelo presente autor, demonstrou-se que a ação do Coetus Internationalis Patrum no Concílio foi importante e fundamental. Demonstrou-se ainda que é impossível ter uma visão global e completa do Vaticano II sem levar tal ação em consideração. Relatou-se a formação e a história do CIP ao longo do Concílio, procurando descrever a evolução de sua organização e estratégia e propondo uma avaliação de seu impacto sobre os textos conciliares. Concluiu-se ainda que o grupo não foi capaz de mudar o espírito ou a perspectiva teológica nas quais os esquemas da "segunda preparação" foram redigidos, mas que teve um impacto considerável sobre eles. O grupo conseguiu: retardar a adoção desses esquemas; moderar o ímpeto dos reformadores - que tinham de propor sempre um texto admissível para a maioria; introduzir nos esquemas proposições que contribuíram para tornar os textos do Vaticano II documentos de compromisso que são passíveis, por vezes, de diversas interpretações.

No fechamento do Concílio, os membros mais importantes do Coetus Internationalis Patrum engajaram-se a continuar o combate contra a interpretação liberal dos textos conciliares. Para tal, eles decidiram fundar uma revista cujo objetivo não era rejeitar ou se opor ao Concílio, mas interpretá-lo de maneira conservadora, denunciando as interpretações que se distanciavam da doutrina tradicional. Após um primeiro projeto que não logrou êxito, uma revista, 
intitulada Fortes in Fide, foi criada; tal revista, no entanto, deixou de ser publicada rapidamente, pois, sua fórmula não era viável.

Os dirigentes do CIP deixaram Roma, portanto, determinados a continuar com a resistência, cada um em sua própria diocese, e a incitar os membros e simpatizantes do grupo - bem como outros bispos - a resistir também. Num primeiro momento, eles lutaram contra a interpretação que eles julgavam "não tradicional" dos documentos conciliares, mas esta posição inconfortável acabou tornando-se insustentável, pois a Igreja ficava cada dia mais envolvida no espírito do Concílio. Era lhes necessário lidar com um Concílio que se opunha à teologia e à doutrina que eles consideravam corretas; era lhes necessário aceitar textos que eles acreditavam ser contrários à doutrina tradicional da Igreja e, com o passar dos anos, aderir a palavras e gestos do papado que eles julgavam em contradição com a doutrina responsável por suas respectivas formações religiosas. Diante dessa situação, as reações foram diferentes: dois dentre eles, Mons. Lefebvre e Antonio de Castro Meyer, opuseram-se fortemente ao Concílio e o rejeitaram; alguns aceitaram-no plenamente; outros trataram de resistir como podiam sem tomar uma posição contrária ao papado e sem se pronunciar contra o Concílio, interpretando-o segundo a teologia tradicional. Essas diferentes formas de "recepção" do Vaticano II pelos antigos membros e simpatizantes do Coetus Internationalis Patrum constituiriam assuntos interessantíssimos a serem estudados. Tal estudo poderia explicar como os membros do CIP viveram o período pós-conciliar, quais foram suas escolhas e quais foram as razões para suas respectivas tomadas de posição em relação ao Concílio. 


\section{REFERÊNCIAS}

ACTA ET DOCUMENTA CONCILIO OECUMENICO VATICANO II APPARANDO. Series I: Antepraeparatoria, Serie II: Praeparatoria. Città del Vaticano: Typis polyglottis vaticanis, 1960-1994.

ACTA SYNODALIA SACROSANCTI CONCILII OECUMENICI VATICANI II. 6 tomos, 35 volumes. Città del Vaticano: Typis polyglottis vaticanis, 1970-2000.

ALBERIGO, Giuseppe (Dir.). Histoire du Concile Vatican II (1959-1965). Tome I, Le catholicisme vers une nouvelle époque. L'annonce et la préparation (Janvier 1959-octobre 1962); Tome II, La formation de la conscience conciliaire. La première session et la première intersession (Octobre 1962-septembre 1963) ; Tome III, Le Concile adulte, La deuxième session et la deuxième intersession (Septembre 1963-septembre 1964); Tome IV, L’Église en tant que communion. La troisième session et la troisième intersession (Septembre 1964-septembre 1965) ; Tome V, Concile de transition. La quatrième session et la conclusion du Concile (Septembre-décembre 1965), version française sous la direction de Étienne FouILlouX, Paris : Éditions du Cerf; Louvain: Éditions Peeters, respectivement 1997; 1998; 2000; 2003; 2005.

ANNUARIO PONTIFÍCIO. Città del Vaticano: Tipografia Poliglotta Vaticana, 1959 a 1965.

ARQUIVOS DA ABADIA BENEDITINA DE SOLESMES (AABS). Solesmes: 1963.

ARQUIVOS DO SEMINÁRIO DE ÉCÔNE (ASE). E02-05, 001. Valais: 1962.

AVALLONE, Emanuele. Mons. Luigi Maria Carli (1914-1986) e il Concilio

Vaticano II: Preparazione, Partecipazione e Ricezione. 2009. 109 p. Dissertation Université pontificale du Latran. Rome, 2009.

BEOZZO, Jose Oscar. A Igreja do Brasil no Concílio Vaticano II 1959-1965. São Paulo: Paulinas, 2005.

BERTO, Victor-Alain. Notre-Dame de Joie: Correspondance de l'abbé V. A. Berto, prêtre 1900-1968. 2. édition. Paris: Nouvelles Éditions Latines, 1989.

BUONASORTE, Nicla. «Per la "pura, piena, integra fede cattolica” : il p. V.A. Berto al concilio Vaticano II ». Cristianesimo nella Storia, Bologna, n. 22, p. 111-151, 2001.

BUONASORTE, Nicla. Siri: Tradizione e Novecento. Bologna : Il Mulino, 2006.

BUONASORTE, Nicla. Tra Roma e Lefebvre: Il tradizionalismo cattolico italiano e il Concilio Vaticano II. Roma: Edizioni Studium, 2003. 
CAPRILE, Giovanni. Il Concilio Vaticano II, 5 vol. en 6 tomes, Vol. I. Annunzio e preparazione I (1959-1960), 438 p. et II (1961-1962), 772 p. ; Vol. II. Il primo periodo (1962-1963), 644 p. ; Vol. III. Il secondo periodo (1963-1964), 674 ; Vol. IV. Il terzo periodo (1964-1965), 584 p. ; Vol. V. Il quarto periodo (1965), 756 p. Roma: La Civiltà Cattolica, 1965-1969.

CONGAR, Yves. Mon Journal du Concile. Paris: Éditions du Cerf, 2002.

COPPE CALDEIRA, Rodrigo. Os baluartes da tradição : o conservadorismo Católico Brasileiro no Concílio Vaticano II. Curitiba: Editora CRV, 2011.

DE MATTEI, Roberto. Le croisé du XX' $X^{\mathbf{e}}$ siècle: Plinio Corrêa de Oliveira. Traduit de l’italien par François Quöex. Lausanne : Éditions L’Age d’Homme, 1997.

DOLDI, Marco. Giuseppe Siri il pastore, 1946-1987. Città del Vaticano: Libreria editrice vaticana, 2006.

FESQUET, Henri. Le journal du Concile. Paris: Robert Morel Forcalquier, 1966.

GAMBINO, Emanuele. Il pastore sulla breccia: Ernesto card. Ruffini. Rome : Editrice Ancora, 1967.

GHEDA, Paolo. Siri, la Chiesa, l'Italia. Genova-Milano: Marietti, 2009.

GÓMEZ DE ARTECHE Y CATALINA, Salvador. Grupos « extra aulam » en el II Concilio Vaticano y su influencia. 1980. 2586 f. 3 v., 9 tomes. Thèse (doctorat) Faculté de Droit de l’Université de Valladolid. Valladolid, 1980.

LAI, Benny. Il Papa non eletto: Giuseppe Siri, cardinale di Santa Romana Chiesa. Rome: Laterza, 1993.

LAURENTIN, René. L'enjeu du Concile, bilan des quatre sessions et bilan général. Paris : Éditions du Seuil. T. 1, L’enjeu du Concile, 1962. T. 2, Bilan de la première session, 1963. T. 3, Bilan de la deuxième session, 1964. T. 4, Bilan de la troisième session, 1965. T. 5, Bilan du Concile, 1967.

LEFEBVRE, Marcel. Ils l'ont découronné: Du libéralisme à l'apostasie. La tragédie conciliaire. Escurolles : Éditions « Fideliter », 1987.

PERRIN, Luc. «Il “Coetus Internationalis Patrum” e la minoranza conciliare », dans L'Evento e le decisioni, Studi sulle dinamiche del concilio Vaticano II, sous la direction de Maria Teresa FATTORI et de Alberto MELLONI, Società editiche Il Mulino. Bologna: Istituto per le scienze religiose, 1997. Testi e ricerche di scienze religiose, nuova serie 20. p. 173-187.

PERRIN, Luc. « Le Coetus Internationalis Patrum et la minorité à Vatican II ». Catholica, Paris, n. 63, p. 71-84, 1999. 
PETRALIA, Giuseppe. Il cardinale Ernesto Ruffini, arcivescovo di Palermo. Città del Vaticano: Libreria Editrice Vaticana, 1989.

ROMANO, Angelo. Ernesto Ruffini, Cardinale arcivescovo di Palermo (1946-1967). Caltanissetta: Sciascia, 2002. (Studi del Centro A. Cammarata).

ROUQUETTE, Robert. La fin d'une chrétienté: chroniques. Paris : Éditions du Cerf, 1968, 2 v. (coll. «Unam Sanctam », 69a-b).

ROY-LYSENCOURT, Philippe. Le Coetus Internationalis Patrum: un groupe d'opposants au sein du concile Vatican II. 2011. 2331 pages. thèse (doctorat) - Lyon 3, Faculté de théologie et de sciences religieuses de l'Université Laval, Département d’Histoire de la Faculté des Lettres et Civilisations de l’Université Jean Moulin. Lyon, 2011.

ROY-LYSENCOURT, Philippe. Les membres du Coetus Internationalis Patrum au concile Vatican II: Inventaire des interventions et souscriptions des adhérents et sympathisants. Liste des signataires d'occasion et des théologiens. Leuven: Maurits Sabbe Library, Faculty of Theology and Religious Studies, Peeters ( Instrumenta theologica » XXXVII), 2014.

SPIAZZI, Raimondo (dir.). Il Cardinale Giuseppe Siri, arcivescovo di Genova dal 1946-1987. Bologna : Edizione Studio Domenicano, 1990.

STABILE, Francesco Michele. « Il Cardinal Ruffini e il Vaticano II: Le lettere di un "intransigente" », Cristianesimo nella storia, Bologna, v. XI/I, p. 83-176, febbraio 1990.

TISSIER DE MALLERAIS, Bernard. Marcel Lefebvre: une vie. Étampes: Clovis, 2002.

WENGER, Antoine. Vatican II: Première session. Paris: Éditions du Centurion, 1963.

WENGER, Antoine. Vatican II: Chronique de la deuxième session. Paris: Éditions du Centurion, 1964.

WENGER, Antoine. Vatican I: Chronique de la troisième session. Paris: Éditions du Centurion, 1965.

WENGER, Antoine. Vatican II: Chronique de la quatrième session. Paris: Éditions du Centurion, 1966.

WHITE, David Allen. The mouth of the lion: Bishop Antonio de Castro Mayer \& the Last Catholic Diocese. Kansas City: Angelus Press, 1993.

WILTGEN, Ralph Michael. Le Rhin se jette dans le Tibre: Le Concile inconnu. Paris: Éditions du Cèdre, 1974. 